\title{
A Case Report of Nasopharyngeal Myiasis in a 49-Year-old Shepherd Man Referred to the Emergency Department of Tabriz
}

\author{
Yagoob Garedaghi $^{1^{*}}$, Iasmina Luca ${ }^{\circledR}$, Muhammad Bilal $^{3}$ \\ ${ }^{1}$ Department of Parasitology, Tabriz Branch, Islamic Azad University, Tabriz, Iran \\ ${ }^{2}$ Department of Parasitology and Dermatology, Banat's University of Agricultural Sciences and Veterinary Medicine "King \\ Michael I of Romania" from Timisoara, Calea Aradului 119, 300645 Timisoara, Romania \\ ${ }^{3}$ School of Life Science and Food Engineering, Huaiyin Institute of Technology, Huai'an, 223003, China
}

\begin{abstract}
Myiasis is an infection of living vertebrates with fly larvae. The disease in humans is caused by parasites that are associated with an animal host. It may also affect patients with some degrees of immunodeficiency and involve different parts of the vertebrate body. This report is a case of nasopharyngeal myiasis in a 49-year-old shepherd who had referred to the emergency department of Tabriz in Iran, and the purpose of this report is to make physicians and nursing staff, who work in the treatment and care of patients, more notified of this ectoparasitic infection.

Keywords: Myiasis, Larvae of flies, Shepherd, Emergency, Tabriz, Iran
\end{abstract}

Received: February 12, 2021, Accepted: February 25, 2021, ePublished: April 1, 2021

\section{Introduction}

Myiasis is a disease caused by the presence of the maggot larvae of dipterous flies (two wings) in the living/dead tissues of living vertebrates. This entry and presence of larvae may occur through wounds and skin lesions or natural body cavities such as the mouth, ears, eyes, and genitourinary system. Although the disease is more common in tropical climates, it is not limited to these areas and is a global agricultural problem in domestic animals. The disease in humans is caused by parasites that are related to an animal host. Cutaneous myiasis is the most common clinical form, and nasopharyngeal myiasis includes nasal-oral-sinus-ear infection, as well as the eye (ophthalmomyiasis) and intestinal myiasis caused by the ingestion of the organism $(1,2)$.

Braid et al reported two cases of nasopharyngeal myiasis in the American Gazette (3). Likewise, Beckendorf et al reported several cases of nasal myiasis in immunocompromised patients in the intensive care unit (4). In another study, Gordon et al found six cases of cutaneous myiasis caused by Dermatobia hominis (5).

In this article, a case of nasopharyngeal myiasis is described so that to increase the awareness of physicians and patient care staff, including nurses, of this ectoparasitic infection.

\section{Case Report}

The patient was a 49-year-old shepherd man who had referred to the emergency department of a hospital in Tabriz, Iran with weakness, lethargy, nausea, and vomiting. He had a history of diabetes and had a blood pressure of $65 / 100$, a heart rate of 35 , and a respiratory rate of 42 at baseline. In addition, the patient had 430 glucose and troponin positive, as well as haematuria and ketonuria in urine analysis.

Hemodynamic status and pulmonary hearing were normal. The patient had jaundice and a series of white worms, which were actually fly larvae, coming out of the patient's mouth and nose.

The larvae were sent to the parasitology laboratory of the Faculty of Veterinary Medicine of the Islamic Azad University of Tabriz for definitive diagnosis.

\section{The Results of the Laboratory Study}

Macroscopic Description

Eight cream-colored larvae with a length of 0.1-0.8 cm and a diameter of $0.1-1.2 \mathrm{~cm}$ were found based on the results (Figure 1).

\section{Microscopic Description and Diagnosis}

In microscopic examinations, the larva had hooks in the mouth, cephalo-pharyngeal part of the esophagus, intestine and trunk, and a pair of posterior claws and cuticle spines (Figure 2). 


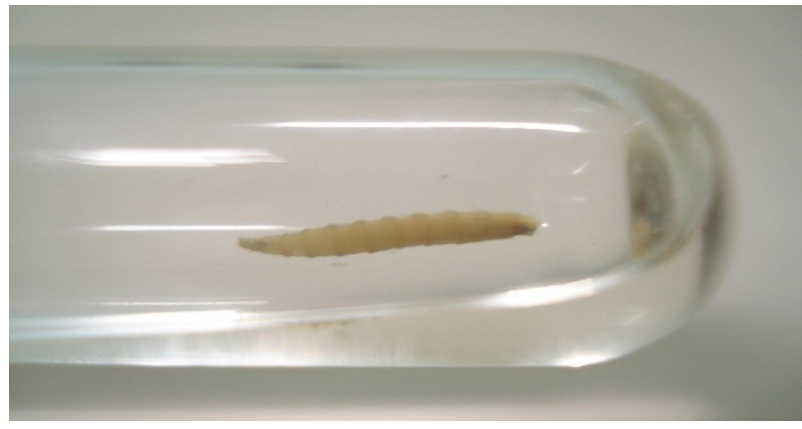

Figure 1. One of the Isolated Maggot larvae in the Test Tube.

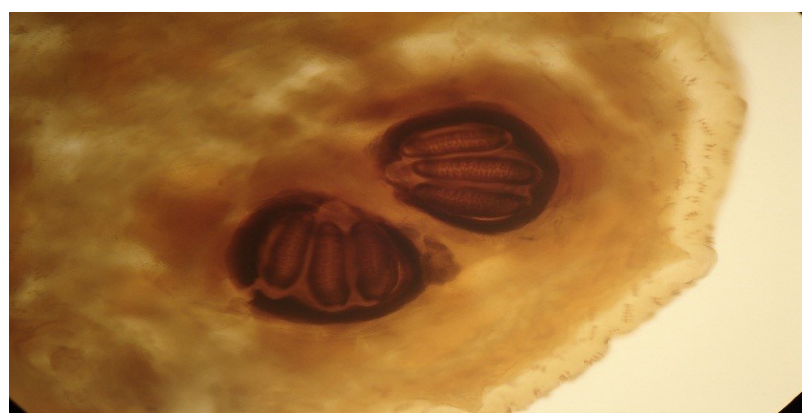

Figure 2. Stigmata (Respiratory Pores) in the Posterior End of Maggot Larvae Under a Light-Microscope.

\section{Discussion}

Myiasis is an ectoparasitic infection of humans and vertebrates. Vertebrates are infected with the larvae of dipterous flies that are called maggots. Myiasis is extremely important in veterinary medicine, and human disease is due to parasites that are associated with animal hosts. The most common form of myiasis is the skin form (cutaneous myiasis). Nasopharyngeal myiasis includes infections of the nose, mouth, sinuses, and ears. Eye (ophthalmomyiasis) and intestinal myiasis caused by the ingestion of the organism are observed as well $(5,6)$.

Dermatobia hominis is one of the causative flies of myiasis. Female flies lay their eggs in shady soils or drying clothes, preferably contaminated with urine or feces. Within one to three days, the fertilized larvae remain close to the soil to be activated by heat (e.g., the heat of a human or animal body). Female flies attach their eggs to the abdomen of bloodthirsty arthropods, including mosquitoes. When a mosquito eats a warm-blooded animal, local heat causes the fertilized larva to fall on the host's skin (Larva stage 1), and the larvae penetrate the skin directly or through the wound caused by the mosquito without causing pain and thus access the dermis and subcutaneous tissue. The second- and third-stage larvae having hooks are formed within 5-10 weeks (7).

\section{Treatment of Myiasis}

The goal of treatment is to clear the tissue from the larvae of flies. If there is myiasis on the wound or skin, the first step is to cover the affected area with a layer of petroleum oils such as paraffin. This blocks the larvae's posterior airways from escaping the wound to receive oxygen, and the larvae should then be removed immediately. If necessary, the larvae must be surgically removed from the affected skin or organ, especially the eyes or ears. In the pharyngeal myiasis, eating the lukewarm oil stimulates the larvae and releases them from the throat mucosa $(8,9)$.

In the case of cutaneous myiasis, hand pressure is sometimes sufficient and is usually performed before visiting a doctor. It can occasionally be caught by forceps by blocking the penetration path to prevent gas exchange. Surgery is almost always required for the migratory form of the disease. In the case of wound myiasis, it is necessary to manually remove all visible larvae, followed by cleaning and occasionally washing the wound. The use of $15 \%$ chloroform in the olive oil or any other oils or even ether immobilizes the larvae. Ivermectin has been used to treat myiasis in animals and at least one human with subcutaneous myiasis (10).

\section{Prevention of Myiasis}

Myiasis infection can be prevented by insecticides containing DDT. It is advised that people living in contaminated areas use head and face protective hats. Ironing clothes is an effective way to remove laid eggs. Further, wearing long-sleeved clothing to cover wounds and avoid sleeping outdoors are other ways to prevent myiasis infection. Moreover, infected tissues and organs such as ears, eyes, and urinary tract should be rapidly treated if there is a purulent discharge. The best and most effective way to control flies is to improve and maintain environmental health, and insecticides should be applied only as a complement to this action rather than a substitute (11).

\section{Acknowledgements}

We would like to express our deep gratitude to Islamic Azad University, Tabriz Branch for offering valuable theoretical and practical assistance to the research team of the present study.

\section{Authors' Contributions}

YG wrote and edited the manuscript. IL and MB designed and collected data.

\section{Conflict of Interests}

The authors declare that they have no conflict of interests.

\section{Ethical Issues}

Ethical considerations were fully observed in this research.

\section{Funding}

The authors received no financial support for the research, authorship, and publication of this article.

\section{References}

1. Ahmet AH, Krafchik BR. The unidentified parasite: a probable case of North American cuterebrid myiasis in a pediatric patient. Pediatr Dermatol. 2004;21(4):515-516. doi:10.1111/ j.0736-8046.2004.21428.x

2. Braunwald E, Fauci AS, Kasper DL, Hauser SL, Longo DL, Jameson JL. Harrison's Principles of Internal Medicine. 15th 
ed. USA: McGraw-Hill; 2000:139-893.

3. Baird JK, Baird CR, Sabrosky CW. North American cuterebrid myiasis. Report of seventeen new infections of human beings and review of the disease. J Am Acad Dermatol. 1989;21(4 Pt 1):763-772.

4. Beckendorf R, Klotz SA, Hinkle N, Bartholomew W. Nasal myiasis in an intensive care unit linked to hospital-wide mouse infestation. Arch Intern Med. 2002;162(6):638-640. doi:10.1001/archinte.162.6.638

5. Gordon PM, Hepburn NC, Williams AE, Bunney $\mathrm{MH}$. Cutaneous myiasis due to Dermatobia hominis: a report of six cases. $\mathrm{Br}$ J Dermatol. 1995;132(5):811-814. doi:10.1111/j.1365-2133.1995.tb00732.x

6. Garedaghi Y. Flea infestation in farm animals and its zoonotic importance in East-Azerbaijan province. Am J Anim Vet Sci. 2011;6(4):193-196.

7. Piña-Tornés AA, Salvador-Fernández CL, Lindao-Camacho
R, González-Longoria-Boada LB, Vintimilla-Burgos NP, Selles Almarales M. Massive cutaneous myiasis mimicking brain invasion. Case report and literature review. Med UIS. 2016;29(2):145-153. doi:10.18273/revmed.v29n2-2016012

8. Dueñas Moreira O, Gámez Sánchez D, González Guerra QM. Cutaneous myiasis in an elderly from an ecuatorian rural community. Medisan. 2017;21(5):590-594.

9. Hall M, Wall R. Myiasis of humans and domestic animals. Adv Parasitol. 1995;35:257-334. doi:10.1016/s0065308x(08)60073-1

10. Angulo L, Rubio B, Zarco C, et al. Multiple furuncular myiasis caused by Dermatobia hominis. J Am Acad Dermatol. 2014;70(5):AB104.

11. Cedeño JA, Keil C, Ocampo JE, Zapata M, Guerrero M. Miasis auricular por Cochliomyia hominovorax. Rev Fac Cien Med (Quito). 2014;39(2):87-90.

(C) 2021 The Author(s); This is an open-access article distributed under the terms of the Creative Commons Attribution License (http:// creativecommons.org/licenses/by/4.0), which permits unrestricted use, distribution, and reproduction in any medium, provided the original work is properly cited. 